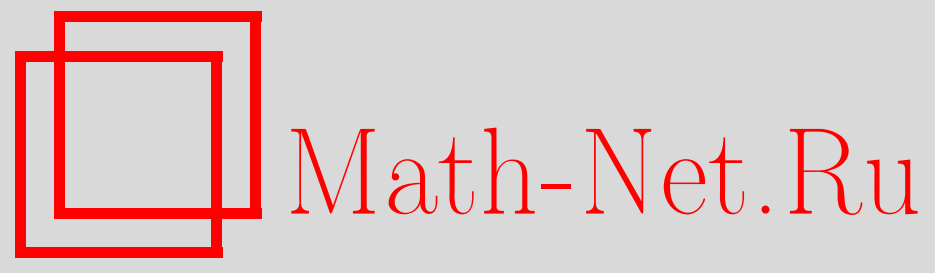

Yu. N. Radayev, V. A. Kovalev, Плоские термоупругие волны в гемитропных микрополярных средах, Вестн. Сам. гос. техн. ун-та. Сер. Физ.-мат. науки, 2019, номер 3, 464-474

DOI: https://doi.org/10.14498/vsgtu1689

Использование Общероссийского математического портала MathNet.Ru подразумевает, что вы прочитали и согласны с пользовательским соглашением

http://www.mathnet.ru/rus/agreement

Параметры загрузки:

IP : 54.198 .64 .247

26 апреля 2023 г., 12:25:01

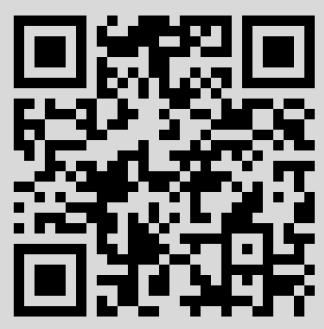




\title{
On plane thermoelastic waves in hemitropic micropolar continua
}

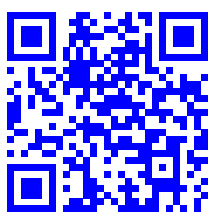

\author{
Y. N. Radayev ${ }^{1}$, V. A. Kovalev ${ }^{2}$ \\ 1 A. Ishlinsky Institite for Problems in Mechanics, Russian Academy of Sciences, \\ 101, pr. Vernadskogo, Moscow, 119526, Russian Federation. \\ 2 Moscow City Government University of Management, \\ 28, Sretenka st., Moscow, 107045, Russian Federation.
}

\begin{abstract}
The paper deals with the coupled heat transport and dynamic equations of the hemitropic thermoelastic micropolar continuum formulated in terms of displacements, microrotations and temperature increment which are to be determined in applied problems. The mechanism of thermal conductivity is considered as simple thermodiffusion. Hemitropic constitutive constants are reduced to a minimum set nevertheless retaining hemitropic constitutive behaviour and thermoelastic semi-isotropy. Solutions of thermoelastic coupled equations in the form of propagating plane waves are studied. Their spatial polarizations are determined. An algebraic bicubic equation for the determination of wavenumbers is obtained. It is found that for a coupled thermoelastic wave actually there are exactly three normal complex wavenumbers. Athermal wave is also investigated. Spatial polarizations in this case form (together with the wave vector) a spatial trihedron of mutually orthogonal directions. For an athermal wave there are (depending on the case) either two real normal wavenumbers or single wavenumber.
\end{abstract}

Keywords: hemitropic, micropolar, thermoelastic, plane wave, wavenumber, polarization, complex amplitude, athermal wave.

Received: $11^{\text {th }}$ April, 2019 / Revised: $3^{\text {rd }}$ August, $2019 /$

Accepted: $26^{\text {th }}$ August, 2019 / First online: $2^{\text {nd }}$ September, 2019

\section{Research Article}

( () (i) The content is published under the terms of the Creative Commons Attribution 4.0 International License (http://creativecommons.org/licenses/by/4.0/)

Please cite this article in press as:

R ad a yev Y. N., Kovalev V. A. On plane thermoelastic waves in hemitropic micropolar continua, Vestn. Samar. Gos. Tekhn. Univ., Ser. Fiz.-Mat. Nauki [J. Samara State Tech. Univ., Ser. Phys. Math. Sci.], 2019, vol. 23, no. 3, pp. 464-474. doi: 10.14498/vsgtu1689.

\section{Authors' Details:}

Yuri N. Radayev (1) https://orcid.org/0000-0002-0866-2151

D.Sc. (Phys. \& Math. Sci.), Ph.D., M.Sc., Professor; Leading Researcher; Lab. of Modeling in Solid Mechanics; e-mail: radayev@ipmnet.ru, y.radayev@gmail.com

Vladimir A. Kovalev (1) https://orcid.org/0000-0003-2991-9531

Dr. Phys. \& Math. Sci., Professor; e-mail: kovalev.kam@gmail.com 
1. Preliminary remarks. The mechanics of hemitropic media is intensively developing, due to the important theoretical significance of its results and methods for the whole of continuum mechanics, as well as due to a wide range of applied problems, where it acts as the basis for modelling the thermomechanical behavior of modern materials and structures. Here we are talking about biological materials (skin, bones, vessels), medical materials have used in transplantology, honeycomb structures, ceramics, foams.

The theory of coupled thermoelasticity of micropolar solids looks now as almost complete (see, for example, [1], where there are also references to early works). The word almost describes significant problems intrinsic to anisotropic micropolar continua. In the general case of material anisotropy, the theory predicts 171 constitutive constants, therefore the handling of equations of anisotropic micropolar continuum presents significant problems. In the hemitropic theory, there are only 9 constitutive constants, three more than in the isotropic case. The group of material symmetry of a hemitropic continuum consists of all proper orthogonal transformations of three-dimensional space, but it does not include such orthogonal transformations that change the orientation of space, for example, inversions.

The present paper primarily aimed at a study of plane harmonic coupled waves of displacements, microrotations and temperature increment in hemitropic micropolar media includes new results concerning evaluation of wavenumbers and spatial polarizations of the amplitude vectors. The paper is arranged as follows. After Preliminary remarks we discuss in Sec. 2 in details a system of dynamic equations of the coupled micropolar thermoelasticity in the hemitropic case and the constitutive constants responsible for thermomechanical coupling. Then a reduced variant of these equations is considered in an attempt to simplify basic equations of the micropolar thermoelasticity theory. Results concerning evaluation of wavenumbers and spatial polarizations of the plane thermoelastic waves are given there. In Sec. 3, a theory of athermal plane waves in micropolar elastic media is given. Conclusions on the present study are discussed in Sec. 4.

2. Plane thermoelastic waves in hemitropic micropolar media: polarizations and wavenumbers. The theory of hemitropic continuum based on three linear strain measures, namely the symmetric small strain tensor, the relative microrotation vector and the spatial gradient of the total microrotation vector (the torsion-curvature tensor), is developed in a number of papers (see, for example, [2]). Nine constitutive constants are so chosen to determine the characteristic micropolar linear scale. This approach is also applicable to the thermoelastic micropolar models. If we employ the conventional notations [1,3], the dynamic equations for displacements and microrotations in the hemitropic thermoelastic micropolar medium can be represented as follows:

$$
\left\{\begin{array}{r}
(\mu+\alpha) \boldsymbol{\nabla} \cdot \boldsymbol{\nabla} \mathbf{u}+(\mu-\alpha+\lambda) \boldsymbol{\nabla} \boldsymbol{\nabla} \cdot \mathbf{u}+(\chi+\nu) \boldsymbol{\nabla} \cdot \boldsymbol{\nabla} \boldsymbol{\phi}+ \\
+(\chi-\nu+\kappa) \boldsymbol{\nabla} \boldsymbol{\nabla} \cdot \boldsymbol{\phi}+2 \alpha \boldsymbol{\nabla} \times \boldsymbol{\phi}-\eta \boldsymbol{\nabla} \theta=\rho \ddot{\mathbf{u}}, \\
(\chi+\nu) \boldsymbol{\nabla} \cdot \boldsymbol{\nabla} \mathbf{u}+(\chi-\nu+\kappa) \boldsymbol{\nabla} \boldsymbol{\nabla} \cdot \mathbf{u}+2 \alpha \boldsymbol{\nabla} \times \mathbf{u}+(\gamma+\varepsilon) \boldsymbol{\nabla} \cdot \boldsymbol{\nabla} \boldsymbol{\phi}+ \\
+(\gamma-\varepsilon+\beta) \boldsymbol{\nabla} \boldsymbol{\nabla} \cdot \boldsymbol{\phi}+4 \nu \boldsymbol{\nabla} \times \boldsymbol{\phi}-4 \alpha \boldsymbol{\phi}-\varsigma \boldsymbol{\nabla} \theta=\mathfrak{I} \ddot{\boldsymbol{\phi}},
\end{array}\right.
$$

wherein $\mathbf{u}$ is the displacement vector, $\boldsymbol{\phi}$ is the microrotation vector, $\theta$ is the temperature increment over the referential temperature $\theta_{0}, \rho$ is the mass density, 
$\mathfrak{I}$ is the microinertia, $\boldsymbol{\nabla}$ is the spatial (3d) Hamilton operator, the rest of the Greek symbols denote mechanical and thermomechanical constitutive constants (among them those denoted by $\eta$ and $\varsigma$ are responsible for the thermomechanical coupling).

Heat propagation in a hemitropic medium in the case of the thermodiffusion mechanism of heat transport is determined by the heat equation

$$
\frac{c}{k} \partial . \theta=\nabla^{i} \nabla_{i} \theta-\frac{\theta_{0}}{k}\left(\eta \partial . \epsilon_{j \cdot}^{\cdot j}+\varsigma \partial . \kappa_{j}^{\cdot j}\right) .
$$

We proceed to comments to the latter equation:

$-\epsilon_{i j}=\nabla_{i} u_{j}-e_{i j k} \phi^{k}$ is the asymmetric strain tensor $\left(e_{i j k}\right.$ is the permutation tensor;

- $\nabla_{i}$ is the operator of covariant differentiation);

$-\kappa_{i}^{\cdot s}=\nabla_{i} \phi^{s}$ is the torsion-curvature tensor or the wryness tensor;

$-\partial$. is the operator of partial differentiation with respect to $t$ (the same as superimposed dot);

- $k$ is the coefficient of thermal conductivity (the heat conduction coefficient);

$-c$ is the heat capacity per unit volume at constant zero strain;

- $\theta_{0}$ is the referential temperature (natural state temperature);

$-\eta=2 G \frac{1+\nu}{1-2 \nu} \stackrel{*}{\alpha}, G$ is the shear modulus of elasticity, $\nu$ is the Poisson ratio, $\stackrel{*}{\alpha}$ is the linear thermal expansion coefficient;

$-\varsigma=2 G L^{2} \stackrel{*}{\beta}, G L^{2}=\gamma, L$ is the micropolar characteristic length, $\stackrel{*}{\beta}$ is the thermal wryness coefficient.

The heat equation (1) complements the dynamic equations to a closed system.

Here we introduce new constants

$$
k^{\prime}=k / \theta_{0}, \quad c^{\prime}=c / \theta_{0}
$$

in order to simplify the heat equation (1) and new notations

$$
k^{\prime} \rightarrow \mathfrak{k}, \quad c^{\prime} \rightarrow \mathfrak{c}
$$

in order to retain for the symbols $k$ and $c$ their usual in wave physics meaning so they will denote the wavenumber and the phase velocity of a wave respectively [4].

In the following, a simplified version of the equations of the coupled thermomechanics of the hemitropic medium is considered, when from the full set of hemitropic terms only the temperature gradient $\varsigma \nabla \theta$ remains. As a result we arrive at the following system of differential equations:

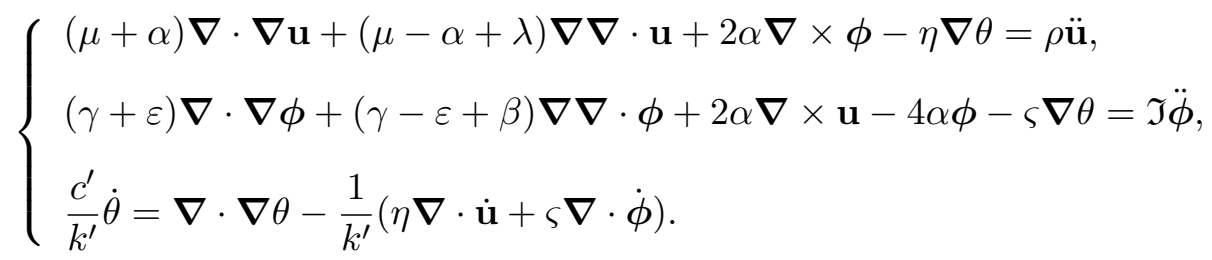

We are going to investigate the solutions of this system in the form of plane waves of displacements, microrotations and temperature:

$$
\mathbf{u}=\mathbf{A} e^{i(\mathbf{k} \cdot \mathbf{r}-\omega t)}, \quad \boldsymbol{\phi}=\mathbf{S} e^{i(\mathbf{k} \cdot \mathbf{r}-\omega t)}, \quad \theta=B e^{i(\mathbf{k} \cdot \mathbf{r}-\omega t)},
$$


where $\mathbf{r}$ is the radius vector; $\mathbf{k}$ is the wave vector; $\omega$ is the cyclic frequency; $\mathbf{A}$, $\mathbf{S}$ are the wave polarization vectors; $B$ is the (complex) temperature increment amplitude.

The wave vector $\mathbf{k}$ and polarization vectors $\mathbf{A}, \mathbf{S}$ must simultaneously satisfy the equations

$$
\begin{aligned}
& -(\mu-\alpha+\lambda)(\mathbf{k} \cdot \mathbf{A}) \mathbf{k}-\left[(\mu+\alpha) k^{2}-\rho \omega^{2}\right] \mathbf{A}+2 \alpha i \mathbf{k} \times \mathbf{S}-\eta i \mathbf{k} B=\mathbf{0}, \\
& -(\gamma-\varepsilon+\beta)(\mathbf{k} \cdot \mathbf{S}) \mathbf{k}-\left[(\gamma+\varepsilon) k^{2}+4 \alpha-\mathfrak{I} \omega^{2}\right] \mathbf{A}+2 \alpha i \mathbf{k} \times \mathbf{A}-\varsigma i \mathbf{k} B=\mathbf{0}, \\
& -k^{2} B+\frac{\mathfrak{c}}{\mathfrak{k}} i \omega B-\frac{\eta}{\mathfrak{k}} \omega(\mathbf{k} \cdot \mathbf{A})-\frac{\varsigma}{\mathfrak{k}} \omega(\mathbf{k} \cdot \mathbf{S})=0,
\end{aligned}
$$

where $k^{2}=\mathbf{k} \cdot \mathbf{k}$. The latter equations are obtained as a result of substitution in the system of differential equations (2) of the displacements, microrotations and temperature in the plane wave (3).

In view of (4), the projections of polarization vectors $\mathbf{A}$ and $\mathbf{S}$ on the wave vector $\mathbf{k}$ are

$$
\begin{aligned}
\mathbf{A} \cdot \mathbf{k} & =\frac{\eta i k^{2} B}{-(\lambda+\mu-\alpha) k^{2}-(\mu+\alpha) k^{2}+\rho \omega^{2}} \\
\mathbf{S} \cdot \mathbf{k} & =\frac{\varsigma i k^{2} B}{-(\beta+\gamma-\varepsilon) k^{2}-(\gamma+\varepsilon) k^{2}-4 \alpha+\mathfrak{I} \omega^{2}}
\end{aligned}
$$

As it is seen from the latter formulae in the coupled thermoelastic wave $(B \neq 0)$, both the polarization vectors $\mathbf{A}$ and $\mathbf{S}$ have nonzero projections on the wave vector $\mathbf{k}$, i.e. as there are longitudinal components of displacements and microrotations the wave is always partially longitudinal. It can be shown that the coupled thermoelastic wave is in fact longitudinal. These projections can be excluded from the system (4), as they are expressed in terms of the complex temperature increment amplitude $B$.

For the squared wavenumber a separate equation can be derived. By introducing the dimensionless wavenumber $\widetilde{k}=k / k_{\|}$and omitting the tilde sign we obtain

$$
\frac{s^{2}}{i \omega^{\prime}} k^{2}+\frac{s_{\|}^{2} k^{2}}{1-k^{2}}+\frac{s_{\|}^{2} k^{2}}{1-\frac{1}{\omega^{\prime 2}}-d_{\|}^{2} k^{2}}=1
$$

where

$$
\begin{aligned}
& \omega^{\prime}=\frac{\omega}{\Omega}, \quad \Omega^{2}=\frac{4 \alpha}{\mathfrak{I}} ; \quad s^{2}=\frac{\Omega \mathfrak{k}}{\mathfrak{c} c_{\|}^{2}}, \quad c_{\|}^{2}=\frac{\lambda+2 \mu}{\rho} ; \\
& s_{\|}^{2}=\frac{\eta^{2}}{\rho \mathfrak{k} c_{\|}^{2}} ; \quad s_{\mu}^{2}=\frac{\varsigma^{2}}{\mathfrak{I} \mathfrak{k} c_{\|}^{2}} ; \\
& d_{\|}^{2}=\frac{{ }_{\mu} c_{\|}^{2}}{c_{\|}^{2}}, \quad{ }_{\mu} c_{\|}^{2}=\frac{\beta+2 \gamma}{\mathfrak{I}} .
\end{aligned}
$$

It should be noted that the equation (6) has no meaning for the wavenumbers given below

$$
k^{2}=1, \quad k^{2}=d_{\|}^{-2}\left(1-\omega^{\prime-2}\right) .
$$


It is easy to demonstrate that these wavenumbers correspond to athermal waves characterized by zero temperature increment amplitude $B=0$.

If instead of cyclic frequency we employ the dimensionless imaginary quantity

$$
\tau^{-1}=i \omega^{\prime}
$$

then for the squared wavenumber the following bicubic equation can be obtained

$$
e_{0} k^{6}+e_{1} k^{4}+e_{2} k^{2}+e_{3}=0
$$

where the coefficients are given by

$$
\begin{aligned}
e_{0} & =-i(i \tau) s^{2} d_{\|}^{2}, \\
-e_{1} & =-i(i \tau) s^{2}\left(d_{\|}^{2}+1-(i \tau)^{2}\right)+\left(1+s^{2}\right) d_{\|}^{2}+{ }_{\mu} s_{\|}^{2}, \\
e_{2} & =\left[1-(i \tau)^{2}\right]\left[-i(i \tau) s^{2}+s_{\|}^{2}+1\right]+{ }_{\mu} s_{\|}^{2}+d_{\|}^{2}, \\
e_{3} & =-\left[1-(i \tau)^{2}\right] .
\end{aligned}
$$

Formal roots of the bicubic equation (7) are to be determined by well known from the higher algebra formula. All of them have nonzero imaginary parts. Three of them correspond to normal wavenumbers. The rest of this Section is devoted to representation of the formal roots of $(7)$.

On a complex plane consider a general algebraic cubic equation ${ }^{1}$

$$
e_{0} w^{3}+e_{1} w^{2}+e_{2} w+e_{3}=0
$$

where $w$ denotes a complex variable; $e_{0}, e_{1}, e_{2}, e_{3}$ are coefficients of the cubic equation treating in general as complex numbers.

Dividing this equation by $e_{0}$ and introducing the new complex variable $w^{\prime}$ in accordance with

$$
w=w^{\prime}-\frac{e_{1}}{3 e_{0}},
$$

we come to the following incomplete cubic equation

$$
\begin{aligned}
& w^{\prime 3}+e_{2}^{\prime} w^{\prime}+e_{3}^{\prime}=0, \\
& e_{2}^{\prime}=\frac{e_{2}}{e_{0}}-\frac{e_{1}^{2}}{3 e_{0}^{2}}, \\
& e_{3}^{\prime}=\frac{2 e_{1}^{3}}{27 e_{0}^{3}}-\frac{e_{1} e_{2}}{3 e_{0}^{2}}+\frac{e_{3}}{e_{0}} .
\end{aligned}
$$

The discriminant of incomplete cubic equation (9) is determined according to

$$
D=-27 e_{3}^{\prime 2}-4 e_{2}^{\prime 3}
$$

and can be recalculated in terms of the coefficients of the original cubic equation (8) as follows:

$$
D=E_{1}^{2} E_{2}^{2}-4 E_{1}^{3} E_{3}-27 E_{3}^{2}-4 E_{2}^{3}+18 E_{1} E_{2} E_{3},
$$

\footnotetext{
${ }^{1}$ The theory of a cubic equation with the required completeness is given, for example, in the classical book [5, pp. 211-217].
} 
wherein

$$
E_{j}=\frac{e_{j}}{e_{0}} \quad(j=1,2,3) .
$$

The formal roots of the incomplete cubic equation are found by using the Cardano formula as the sum of two cubic radicals (they will be denoted by $\lambda$ and $\mu$ )

$$
w^{\prime}=\sqrt[3]{-\frac{e_{3}^{\prime}}{2}+\sqrt{-\frac{D}{4 \cdot 27}}}+\sqrt[3]{-\frac{e_{3}^{\prime}}{2}-\sqrt{-\frac{D}{4 \cdot 27}}}
$$

while implying operating with cubic radicals from complex numbers. The cubic radical of the complex number $z$ has three values; if one $\sqrt[3]{z}=\xi$ is found, then the other two will be equalled to $\varepsilon \xi, \varepsilon^{2} \xi$, where

$$
\varepsilon=\frac{-1+i \sqrt{3}}{2}, \quad \varepsilon^{2}=\frac{-1-i \sqrt{3}}{2} .
$$

Therefore, the Cardano formula (11) under all possible interpretations of the two cubic radicals entered it gives nine values, six of which are discarded by considering the condition that the product of the cubic radicals observed in (11) must be equalled to $-\frac{1}{3} e_{2}^{\prime}$. If a combination of cubic radicals $w^{\prime}=\lambda+\mu$ in the formula (11), which satisfies the equation $\lambda \mu=-\frac{1}{3} e_{2}^{\prime}$, is found, then the combination itself is a root of the equation (9) and the other two roots will have the values $w^{\prime}=\varepsilon \lambda+\varepsilon^{2} \mu, w^{\prime}=\varepsilon^{2} \lambda+\varepsilon \mu$. With a nonzero discriminant all three roots of an incomplete cubic equation are different.

In the case when all of the coefficients $e_{0}, e_{1}, e_{2}, e_{3}$ of the cubic equation (8) are real, the following three cases can be discriminated according to the sign of the discriminant of the equation (10):

1) $D=0$, all roots of the equation (9) are real; the roots are $\frac{3 e_{3}^{\prime}}{e_{2}^{\prime}}$ and $-\frac{3 e_{3}^{\prime}}{2 e_{2}^{\prime}}$ (the double root);

2) $D<0$, under the signs of cubic radicals in (11) there will be real values, therefore the cubic radicals $\lambda, \mu$ can be taken as real; one root of the equation (9) is real and reads $w^{\prime}=\lambda+\mu$, and the two remaining roots

$$
w^{\prime}=-\frac{\lambda+\mu}{2}+\frac{i \sqrt{3}}{2}(\lambda-\mu), \quad w^{\prime}=-\frac{\lambda+\mu}{2}-\frac{i \sqrt{3}}{2}(\lambda-\mu)
$$

are complex conjugates;

3) $D>0$, the cubic radicals $\lambda, \mu$ are complex conjugates; the pairs $\varepsilon \lambda, \varepsilon^{2} \mu$ and $\varepsilon^{2} \lambda, \varepsilon \mu$ are also complex conjugates; all three roots of the equation (9) are real and equalled to $2 \Re \lambda,-\Re \lambda-\sqrt{3} \Im \lambda,-\Re \lambda+\sqrt{3} \Im \lambda$.

3. Athermal plane wave in micropolar media. For an athermal plane wave propagating in micropolar elastic medium the zero temperature increment amplitude takes place, i.e. $B=0$.

In this case, we are talking about hyperbolic model of wave propagation [6]. The polarization vectors $\mathbf{A}, \mathbf{S}$ of the athermal wave according to (5) have no projections on the wave vector $\mathbf{k}$, i.e. the athermal wave is transvers:

$$
\mathbf{A}=\mathbf{A}_{\perp}, \quad \mathbf{S}=\mathbf{S}_{\perp} .
$$


The system (4) for the athermal wave looks much more simple and reads

$$
\begin{aligned}
& -\left((\mu+\alpha) k^{2}-\rho \omega^{2}\right) \mathbf{A}+2 \alpha i \mathbf{k} \times \mathbf{S}=\mathbf{0}, \\
& -\left((\gamma+\varepsilon) k^{2}+4 \alpha-\Im \omega^{2}\right) \mathbf{S}+2 \alpha i \mathbf{k} \times \mathbf{A}=\mathbf{0} .
\end{aligned}
$$

It can be found from the second equation of system (12) that the polarization vectors $\mathbf{A}, \mathbf{S}$ are mutually orthogonal and

$$
2 \mathbf{S}=i \Omega^{2} \frac{\mathbf{k} \times \mathbf{A}}{{ }_{\mu} c_{\perp}^{2} k^{2}+\Omega^{2}-\omega^{2}},
$$

where

$$
{ }_{\mu}^{\prime \prime} c_{\perp}^{2}=\frac{\gamma+\varepsilon}{\mathfrak{I}} .
$$

By substituting $\mathbf{S}$ known from (13) in the first equation of system (12) we obtain

$$
\left[-\rho\left({ }_{\mu}^{\prime \prime} c_{\perp}^{2} k^{2}-\omega^{2}\right)+\frac{\alpha \Omega^{2} k^{2}}{{ }_{\mu}^{\prime \prime} c_{\perp}^{2} k^{2}+\Omega^{2}-\omega^{2}}\right] \mathbf{A}=\mathbf{0} .
$$

It is then seen that

$$
-\rho\left({ }_{\mu}^{\prime \prime} c_{\perp}^{2} k^{2}-\omega^{2}\right)+\frac{\alpha \Omega^{2} k^{2}}{{ }_{\mu} c_{\perp}^{2} k^{2}+\Omega^{2}-\omega^{2}}=0,
$$

or introducing dimensionless quantity

$$
\widetilde{k}=\frac{k}{" k_{\perp}}
$$

where

$$
" k_{\perp}^{2}=\frac{\omega^{2}}{" c_{\perp}^{2}}, \quad " c_{\perp}^{2}=\frac{\mu+\alpha}{\rho},
$$

and omitting the tilde sign over $k$ finally the following equation can be given

$$
\left.\left[k^{2}-1\right]\left[{ }_{\mu} d_{\perp}^{2} k^{2}-\left(1-(i \tau)^{2}\right)\right)\right]=(i \tau)^{2} d_{\perp}^{2} k^{2} .
$$

In this equation we use the new symbols

$$
d_{\perp}^{2}=\frac{{ }^{\prime} c_{\perp}^{2}}{{ }^{\prime} c_{\perp}^{2}}, \quad{ }^{\prime} c_{\perp}^{2}=\frac{\alpha}{\rho}, \quad{ }_{\mu} d_{\perp}^{2}=\frac{{ }^{\prime \prime} c_{\perp}^{2}}{{ }_{\mu} c_{\perp}^{2}} .
$$

Corresponding to an athermal wave the values of $k$ are determined from a biquadratic equation (14) and are presented here as

$$
2_{\mu} d_{\perp}^{2} k_{1,2}^{2}=(i \tau)^{2} d_{\perp}^{2}+{ }_{\mu} d_{\perp}^{2}+1-(i \tau)^{2} \pm \sqrt{\mathscr{D}},
$$

wherein

$$
\mathscr{D}=\left[(i \tau)^{2} d_{\perp}^{2}-{ }_{\mu} d_{\perp}^{2}+\left(1-(i \tau)^{2}\right)\right]^{2}+4(i \tau)^{2}{ }_{\mu} d_{\perp}^{2} d_{\perp}^{2}
$$


It is clearly seen that the discriminant $\mathscr{D}$ is positive:

$$
\mathscr{D}>0
$$

therefore the both values of $k^{2}$ given by (15) are real.

Since

$$
k_{1}^{2} k_{2}^{2}=\frac{1-(i \tau)^{2}}{{ }_{\mu} d_{\perp}^{2}},
$$

if $1>(i \tau)^{2}$ then the both values $k_{1}^{2}$ and $k_{2}^{2}$ are positive, otherwise (when $1<(i \tau)^{2}$ ) the first value $k_{1}^{2}$ is positive whereas the second $k_{2}^{2}$ is negative.

We proceed to discussion of the first case assuming $1>(i \tau)^{2}$. The wavenumbers of athermal wave are found as four real values

$$
\sqrt{2}{ }_{\mu} d_{\perp} k_{1,2 ; 3,4}= \pm \sqrt{(i \tau)^{2} d_{\perp}^{2}+{ }_{\mu} d_{\perp}^{2}+1-(i \tau)^{2} \pm \sqrt{\mathscr{D}}}
$$

among them only two are normal: $k_{1 ; 3}$ and $k_{1 ; 4}$.

In the second case discriminated by the inequality $1<(i \tau)^{2}$ there is single normal wavenumber thus concluding that if $(i \tau)^{2}<1$ then there are two real normal wavenumbers, otherwise $\left((i \tau)^{2}>1\right)$ - single wavenumber.

\section{Conclusions.}

1. The coupled thermal and dynamic equations for the hemitropic micropolar medium have been formulated in terms of displacements, microrotations and temperature. The equation of thermal conductivity corresponds to the thermodiffusion mechanism of heat transport.

2. Constitutive constants of hemitropic thermoelastic media have been reduced to a minimum set nevertheless retaining hemitropic thermoelastic constitutive behaviour.

3. Solutions of the coupled thermoelastic equations in the form of propagating plane waves of displacements, microrotations and temperature have been investigated.

4. A plane thermoelastic wave is characterized by spatial polarizations, which have longitudinal components. Bicubic equation for the wavenumber is obtained. It has been shown that there were exactly three normal complex wavenumbers.

5. The athermal wave has been studied. Spatial polarizations in this case form (together with the wave vector) an orthogonal trihedron in space. Wavenumbers have been determined from the biquadratic equation. For an athermal wave depending on case, either two real normal wavenumbers or single wavenumber are found.

Competing interests. We declare that we have no competing interests.

Authors' contributions and responsibilities. Each author has participated in the article concept development and in the manuscript writing. The authors are absolutely responsible for submitting the final manuscript in print. Each author has approved the final version of manuscript.

Funding. This study was in part financially supported by the Ministry of Science and Higher Education (State Registration Number AAAA-A17-117021310381-8) and by the Russian Foundation for Basic Research (project no. 18-01-00844_a). 
Acknowledgments. The authors are grateful to the referee for careful reading of the paper and valuable suggestions and comments.

\section{References}

1. Nowacki W. Theory of Asymmetric Elasticity. Oxford, Pergamon Press, 1986, viii +383 pp.

2. Radayev Y. N. The Lagrange multipliers method in covariant formulations of micropolar continuum mechanics theories, Vestn. Samar. Gos. Tekhn. Univ., Ser. Fiz.-Mat. Nauki [J. Samara State Tech. Univ., Ser. Phys. Math. Sci., 2018, vol. 22, no. 3, pp. 504-517 (In Russian). doi : 10.14498/vsgtu1635.

3. Nowacki W. Theory of micropolar elasticity, International Centre for Mechanical Sciences. Courses and Lectures, vol.25. Wien, Springer-Verlag, 1972, 286 pp. doi: 10.1007/ 978-3-7091-2720-9.

4. Brekhovskikh L. M., Goncharov V. V. Introduction to Continuum Mechanics (in Application to Theory of Waves). Moscow, Nauka Publ., 1982, 336 pp. (In Russian)

5. Sushkevich A. K. Foundations of Higher Algebra. Moscow, Leningrad, ONTI, 1937, 476 pp. (In Russian)

6. Radayev Y. N. Hyperbolic theories and applied problems of solid mechanics, In: "Actual Problems of Mechanics", Int. Conf., Dedicated to L. A. Galin 100th Anniversary (September, 20-21, 2012. Moscow), Book of Abstracts. Moscow, IPMech RAS, 2012, pp. 75-76 (In Russian). 
Вестн. Сам. гос. техн. ун-та. Сер. Физ.-мат. науки. 2019. Т. 23, № 3. С. 464-474 ISSN: 2310-7081 (online), 1991-8615 (print)

УДК 539.3

\title{
Плоские термоупругие волны в гемитропных микрополярных средах
}

\author{
Ю. Н. Радаев ${ }^{1}$, В. А. Ковалев ${ }^{2}$ \\ 1 Институт проблем механики им. А. Ю. Ишлинского РАН, \\ Россия, 119526, Москва, просп. Вернадского, 101, корп. 1. \\ 2 Московский городской университет управления Правительства Москвы, \\ Россия, 107045, Москва, ул. Сретенка, 28.
}

\section{Аннотация}

Рассматриваются связанные термические и динамические уравнения гемитропной термоупругой микрополярной среды относительно подлежащих определению полей перемещений, микровращений и температурного инкремента. Механизм теплопроводности предполагается термодиффузионным. Определяющие постоянные гемитропного термоупругого тела редуцированы к минимальному набору, обеспечивающему его термоупругую полуизотропность. Изучаются решения связанных уравнений в форме распространяющихся плоских волн. Определены их пространственные поляризации. Получено алгебраическое бикубическое уравнение для определения волновых чисел и установлено, что для связанной волны в действительности существуют ровно три нормальных комплексных волновых числа. Исследуется также холодная атермическая волна. Пространственные поляризации в этом случае образуют (вместе с волновым вектором) триэдр взаимно ортогональных направлений. Для атермической волны находятся (в зависимости от случая) либо два вещественных нормальных волновых числа, либо одно.

Ключевые слова: гемитропный, микрополярный, термоупругий, плоская волна, поляризация, комплексная амплитуда, атермическая волна.

Получение: 11 апреля 2019 г. / Исправление: 3 августа 2019 г. Принятие: 26 августа 2019 г. / Публикация онлайн: 2 сентября 2019 г.

Конкурирующие интересы. Заявляем, что в отношении авторства и публикации этой статьи конфликта интересов не имеем.

\section{Научная статья}

(2) (ㄱ) Контент публикуется на условиях лицензии Creative Commons Attribution 4.0 International (https://creativecommons.org/licenses/by/4.0/deed.ru)

\section{Образец для цитирования}

R a d a yev Y. N., Kovalev V. A. On plane thermoelastic waves in hemitropic micropolar continua, Vestn. Samar. Gos. Tekhn. Univ., Ser. Fiz.-Mat. Nauki [J. Samara State Tech. Univ., Ser. Phys. Math. Sci.], 2019, vol. 23, no. 3, pp. 464-474. doi: 10.14498/vsgtu1689.

\section{Сведения об авторах}

Юрий Николаевич Радаев (1) https://orcid.org/0000-0002-0866-2151

доктор физико-математических наук, профессор; ведущий научный сотрудник; лаб. моделирования в механике деформируемого твердого тела; e-mail:radayev@ipmnet.ru, y.radayev@gmail.com

Владимир Александрович Ковалев (1) https://orcid.org/0000-0003-2991-9531

доктор физико-математических наук, профессор; e-mail: kovalev.kam@gmail.com 
Авторский вклад и ответственность. Все авторы принимали участие в разработке концепции статьи и в написании рукописи. Авторы несут полную ответственность за предоставление окончательной рукописи в печать. Окончательная версия рукописи была одобрена всеми авторами.

Финансирование. Работа выполнена при частичной финансовой поддержке Министерства науки и высшего образования (номер государственный регистрации ААААА17-117021310381-8) и Российского фонда фундаментальных исследований (проект № 18-01-00844_a).

Благодарности. Авторы благодарят рецензента за внимательное прочтение статьи, ценные предложения и комментарии. 